OPEN ACCESS

Edited by:

Ling Wu

Soochow University, China

Reviewed by:

Yuniian Liu,

Jiangsu University, China

Wei Xiao,

Yangtze University, China

${ }^{*}$ Correspondence:

Zhao Fang

fangzhao@xauat.edu.cn

Linbo Li

linboli73@126.com

Specialty section

This article was submitted to

Electrochemistry,

a section of the journal

Frontiers in Chemistry

Received: 28 July 2020 Accepted: 31 August 2020 Published: 06 October 2020

Citation:

Fang Z, Zheng Z, Cheng W, Zhang X, Zhong K and Li L (2020) Mechanism of Stability Enhancement for Adiponitrile High Voltage Electrolyte System Referring to Addition of Fluoroethylene Carbonate.

Front. Chem. 8:588389.

doi: 10.3389/fchem.2020.588389

\section{Mechanism of Stability Enhancement for Adiponitrile High Voltage Electrolyte System Referring to Addition of Fluoroethylene Carbonate}

\author{
Zhao Fang ${ }^{1,2 *}$, Zekun Zheng ${ }^{1}$, Wudan Cheng ${ }^{1}$, Xingliang Zhang ${ }^{1}$, Kenan Zhong ${ }^{1}$ and \\ Linbo $\mathrm{Li}^{1,2 *}$ \\ 'School of Metallurgical Engineering, Xi'an University of Architecture and Technology, Xi'an, China, ${ }^{2}$ Shaanxi Province \\ Metallurgical Engineering and Technology Research Centre, Xi'an, China
}

In order to improve the stability of high voltage electrolyte for $5 \mathrm{~V}$-level $\mathrm{LiNi}_{0.5} \mathrm{Mn}_{1.5} \mathrm{O}_{4}$ cathode material, adiponitrile (ADN) with high oxidation stability was selected as the main solvent, meanwhile, $2 \%$ fluoroethylene carbonate (FEC) as the additive with good film forming effect was also used. And then, the effect of $2 \mathrm{~mol} \mathrm{~L}^{-1} \mathrm{LiBF}_{4}-\mathrm{GBL} / \mathrm{ADN}+2 \%$ FEC on the electrochemical performance of $\mathrm{LiNi}_{0.5} \mathrm{Mn}_{1.5} \mathrm{O}_{4}$ was explored at room temperature. The electrolyte system containing FEC can improve the cycle stability of the battery. At $1 \mathrm{C}$ rate, the cycle capacity retention rate can reach $83 \%$ after 100 cycles, while the capacity retention rate of the electrolyte system without FEC and the ordinary commercial electrolyte system is only 77 and $68 \%$, respectively. Besides, the rate performance of the battery with the addition of FEC also shows excellent performance, however, this kind of advantage is not obvious under the conditon of large rate. In addition, under the conditon of the synergistic effect between adiponitrile and fluoroethylene carbonate, the high-voltage electrolyte exhibits the good compatibility and lithium reversibility in the full cell with $\mathrm{Li}_{4} \mathrm{Ti}_{5} \mathrm{O}_{12}$ as the negative electrode.

Keywords: lithium ion battery, adiponitrile, fluoroethylene carbonate, additives, $\gamma$-butyrolactone, high voltage

\section{INTRODUCTION}

Improving the energy density of the battery can be carried out from the perspective of increasing the operating voltage of the battery. It is necessary to explore a high-voltage resistant electrolyte which matches the $5 \mathrm{~V}$-level high-voltage cathode material $\mathrm{LiNi}_{0.5} \mathrm{Mn}_{1.5} \mathrm{O}_{4}$. At present, researchers have invested a lot of efforts in the research of $5 \mathrm{~V}$ high-voltage cathode materials. $\mathrm{LiNi}_{0.5} \mathrm{Mn}_{1.5} \mathrm{O}_{4}$ is a new material obtained by modifying the structure and element reference of the original spineltype material $\mathrm{LiMn}_{2} \mathrm{O}_{4}$ as well as adding a small amount of nickel element, and its specific capacity is the same as that of lithium manganite. While, the working voltage is $17 \%$ higher than that of lithium manganese high-pressure materials (Talyosef et al., 2007). The positive electrode spinel type material $\mathrm{LiNi}_{0.5} \mathrm{Mn}_{1.5} \mathrm{O}_{4}$ charge and discharge platform up to $4.7 \mathrm{~V}$ (Zhou et al., 2012), it's specific capacity is $146.7 \mathrm{mAh} \mathrm{g}^{-1}$, the actual specific capacity is $125 \sim 135 \mathrm{mAh} \mathrm{g}^{-1}$, the reversible specific capacity can reach $133 \mathrm{mAh} \mathrm{g}^{-1}$ and the energy density is up to about 650 Wh $\mathrm{kg}^{-1}$ (Kim et al., 2004; Santhanam and Rambabu, 2010; Zhou et al., 2012; Wang, 2015). The high operating voltage platform meets the demand for high energy density of lithium ion batteries. However, the main problem of $\mathrm{LiNi}_{0.5} \mathrm{Mn}_{1.5} \mathrm{O}_{4}$ is that during cycling, manganese ions 
dissolve from the overall material into the electrolyte, especially at higher temperatures and pressures, resulting in a rapid decline in battery discharge specific capacity and columbic efficiency will also fall (Yoon et al., 2012; Manthiram et al., 2014). Also under high voltage conditions, LNMO-based batteries containing organic carbonate solvent electrolytes have serious capacity decay problems, which are related to electrolyte decomposition and simultaneous degradation reactions at the electrode/electrolyte interface, especially at high temperatures. Due to the thermal instability of $\mathrm{LiPF}_{6} /$ carbonate electrolyte, the evolution of toxic decomposition products, and the accelerated decomposition reaction between the electrolyte and the electrode, the dissolution of manganese ions and nickel ions increases, the irreversible capacity of the battery increases, and the electrochemical cycle performance is seriously degraded (Arunkumar and Manthiram, 2005). Xiang et al. (2008) added dimethyl methylphosphonate (DMMP) flame retardant additives to $1 \mathrm{M} \mathrm{LiPF} / \mathrm{EC}+\mathrm{DMC}$, although the safety performance of the $\mathrm{LiNi}_{0.5} \mathrm{Mn}_{1.5} \mathrm{O}_{4}$ $\mathrm{Li}_{4} \mathrm{Ti}_{5} \mathrm{O}_{12}$ full battery was improved, but the overall working voltage did not meet the demand for high energy density.

According to research, fluorine atoms are extremely electronegative and have strong electron-withdrawing capabilities. The fluorinated solvent of highest occupied orbital energy level and the lowest unoccupied orbital energy level are lower than the traditional carbonate solvent, that is, the oxidation potential and reduction potential of the fluorinated solvent are higher than the traditional carbonate solvent (Michan et al., 2016). Fluorinated ethylene carbonate (FEC) is often used as a high-pressure resistant solvent or negative electrode solid electrolyte interface film (SEI film) film-forming add itive, and its film-forming effect is good (Choi et al., 2006; Wu et al., 2013; Markevich et al., 2014). Although the literature shows TMSP additives also help MCMB anode and $\mathrm{LiNi}_{0.5} \mathrm{Mn}_{1.5} \mathrm{O}_{4}$ cathode to form a thicker and more conductive SEI layer, for $\mathrm{Li}_{4} \mathrm{Ti}_{5} \mathrm{O}_{12}$ anode, FEC can exert better compatibility (Lu et al., 2019). In the current work, high concentration $\mathrm{LiBF}_{4} / \mathrm{GBL}$ electrolyte solution is used to improve the charge / discharge performance of graphite anode and $\mathrm{LiNi}_{0.5} \mathrm{Mn}_{1.5} \mathrm{O}_{4}$ cathode (Sawai and Ohzuku, 2003; Ufheil et al., 2005). In previous studies, researchers usually used $\gamma$-butyrolactone (GBL) or glutaronitrile (GLN) as a co-solvent containing more than $10 \%$ in the standard electrolyte system, which improved the cycle performance of the battery (Duncan et al., 2013). Adiponitrile (ADN) shows the best thermal stability, low viscosity and high dielectric constant in many dinitrile-based solvents (Abu-Lebdeh and Davidson, 2009; Isken et al., 2011; Douaa et al., 2018). The most remarkable feature of this kind of substance is that it can still ensure that the electrolyte has an electrochemical window of about $7.0 \mathrm{~V}$ when used alone, and can still maintain $6.0 \sim 6.5 \mathrm{~V}$ in binary or ternary electrolyte (Kirshnamoorthy et al., 2018). Adiponitrile (ADN) has high oxidation stability under high pressure. According to reports, using $\mathrm{ADN}$ and $\mathrm{DMC}$ as binary solvents and adding fluoroethylene carbonate can improve the cycle performance of graphite/LFMP full batteries at $4.4 \mathrm{~V}$, and FEC makes the battery cycle efficiency reach $99.9 \%$ or more (Ehteshami et al., 2018).

Based on the demand for high-energy density and high-power lithium-ion batteries and the problems and the analysis of the high-pressure resistant electrolyte mentioned above, this paper is committed to optimizing the electrochemical performance of electrolyte for the high-voltage material $\mathrm{LiNi}_{0.5} \mathrm{Mn}_{1.5} \mathrm{O}_{4}$. The binary solvent system $\left[\mathrm{LiBF}_{4} / \gamma\right.$-butyrolactone $(\mathrm{GBL})$ and adiponitrile $(\mathrm{ADN})]$ with a wide electrochemical window was used to obtain an electrolyte solution with high oxidation stability. And then, fluoroethylene carbonate (FEC) with filmforming as an additive was used to increase the overall oxidation stability of the electrolyte and reduce the interface resistance, finally optimize the overall performance of the high-pressure electrolyte. Meanwhile, the mechanism of synergistic effect between $\mathrm{ADN}$ and FEC on high voltage system was also analyzed.

\section{EXPERIMENTAL SECTION}

\section{Electrolyte Preparations}

The electrolyte is prepared in argon-filled atmosphere, and the moisture and oxygen values in the glove box are required to be $<2 \mathrm{ppm}$. Four electrolytes need to be prepared, the reference electrolyte: commercial electrolyte $1.0 \mathrm{M} \mathrm{LiPF}_{6}$ (EC:EMC = 3:7, volume ratio); comparison electrolyte 1st: 2 vt.\% FEC additive was added to $1.0 \mathrm{M} \mathrm{LiPF}_{6}$ (EC:EMC $=3: 7$, volume ratio) standard electrolyte; comparison electrolyte $2 \mathrm{nd}: 2 \mathrm{~mol} \mathrm{~L}^{-1}$ $\mathrm{LiBF}_{4}$-GBL/ADN (1:1, volume ratio); target electrolyte: $2 \mathrm{~mol}$ $\mathrm{L}^{-1} \mathrm{LiBF}_{4}-\mathrm{GBL} / \mathrm{ADN}$ (1:1, volume ratio)+2\% FEC.

\section{Cell Preparations}

$\mathrm{LiNi}_{0.5} \mathrm{Mn}_{1.5} \mathrm{O}_{4}$ active material, Super $\mathrm{P}$ and polyvinylidene fluoride (PVDF) according to the mass ratio of 93:3:4 $\left(\mathrm{Li}_{4} \mathrm{Ti}_{5} \mathrm{O}_{12}\right.$ is $86: 7.7: 6.3)$ are mixed, and apply the prepared slurry to a clean aluminum foil with a spatula. The coating thickness is controlled to $0.1 \mathrm{~mm}$. Next, the coated pole pieces are dried in a blast drying oven for half an hour, and then taken out and punched into $15 \mathrm{~mm}$ pole pieces with a punching machine. The cut pole pieces are moved to a $120^{\circ} \mathrm{C}$ vacuum drying box for $12 \mathrm{~h}$ for drying to remove NMP and moisture.

\section{Measurements}

Assemble the batteries of $\mathrm{LiNi}_{0.5} \mathrm{Mn}_{1.5} \mathrm{O}_{4} / \mathrm{Li}$ and $\mathrm{LiNi}_{0.5} \mathrm{Mn}_{1.5} \mathrm{O}_{4}$ with case model CR2032. The electrode is a lithium sheet with a diameter of $15.6 \mathrm{~mm}$, and the separator is a polypropylene film with a diameter of $20 \mathrm{~mm}$. After completion, it is necessary to stand at a constant temperature for $12 \mathrm{~h}$ to fully contact the separator and the pole piece for the electrolyte. Finally the batteries are subjected to a constant current charge and discharge test: $\mathrm{LiNi}_{0.5} \mathrm{Mn}_{1.5} \mathrm{O}_{4} / \mathrm{Li}$ half-cells are pre-circulated with a current of $0.1 \mathrm{C}$ for 3 turns to achieve the formation effect, so that the active material can fully exert its performance, and then cycled with a current of $1 \mathrm{C}$ for 100 turns, with a voltage range of $3 \sim 4.9 \mathrm{~V}$. The voltage range of $\mathrm{LiNi}_{0.5} \mathrm{Mn}_{1.5} \mathrm{O}_{4} / \mathrm{Li}_{4} \mathrm{Ti}_{5} \mathrm{O}_{12}$ full battery is $2-3.5 \mathrm{~V}$, test the cycle and rate performance of the batteries. Cyclic voltammetry (CV) curve scanning uses $\mathrm{LiNi}_{0.5} \mathrm{Mn}_{1.5} \mathrm{O}_{4}$ electrode as working electrode, metal lithium sheet as reference electrode and counter electrode, the scan voltage range is $2.7-4.5$ and $3-4.9 \mathrm{~V}$ with a scan voltage rate of $0.1 \mathrm{mV} \mathrm{s}^{-1}$. The frequency range of electrochemical AC impedance is $0.01-105 \mathrm{~Hz}$, and the disturbance amplitude is 
$5 \mathrm{mV}$. Scanning electron microscope (Zeiss supra55), X-ray photoenergy spectroscopy (Japan Rigaku Smartlab9) and X-ray diffraction (Escalab 250Xi) were used to characterize and analyze the mechanism of action of electrolytes and materials.

\section{RESULTS AND DISCUSSION}

Figure 1 shows the cyclic voltammetry test of the LNMO/LTO full battery in three electrolyte systems at room temperature, and the test conditions are $2-3.5 \mathrm{~V}, 0.01 \mathrm{mV} \mathrm{s}^{-1}$. The redox peak around $2.45 \mathrm{~V}$ in the figure belongs to $\mathrm{Mn}^{3+} / \mathrm{Mn}^{4+}$, which is caused by the oxidation reaction and the reduction reaction of $\mathrm{Mn}^{3+} / \mathrm{Mn}^{4+}$, when the $\mathrm{LiNi}_{0.5} \mathrm{Mn}_{1.5} \mathrm{O}_{4}$ active material is charged at a lower voltage. A small charge and discharge platform around $2.45 \mathrm{~V}$ can be corroborated. Two oxidation peaks appeared near $3.15 \mathrm{~V}$, corresponding to $\mathrm{Ni}^{2+} / \mathrm{Ni}^{3+}, \mathrm{Ni}^{3+} / \mathrm{Ni}^{4+}$, but only one obvious reduction peak $\left(\mathrm{Ni}^{3+} / \mathrm{Ni}^{2+}\right)$ and one weak reduction peak $\left(\mathrm{Ni}^{4+} / \mathrm{Ni}^{3+}\right)$. This is because the oxidation state of $\mathrm{Ni}^{3+} / \mathrm{Ni}^{4+}$ is lower than the average oxidation state of the transition. Then in the process of $\mathrm{Ni}^{3+} / \mathrm{Ni}^{4+}$ transition, $\mathrm{Li}^{+}$migration will encounter more repulsion. and in transition balance, $\mathrm{Ni}^{3+} / \mathrm{Ni}^{4+}$ is more balanced than $\mathrm{Ni}^{2+} / \mathrm{Ni}^{3+}$ transition, overcoming more energy barriers shows a very weak redox peak.
After the battery undergoes the first cycle, the CV peaks of the second and third cycles become well-matched and tend to be stable. In comparison, the $\mathrm{CV}$ peaks of the initial three cycles for the battery using the reference electrolyte exhibit the large changes of current, indicating that the SEI film formed during the oxidative decomposition of the reference electrolyte is unstable, causing the electrolyte to continue to decompose, and resulting in capacity loss. For the battery with FEC, the change of current is small, and after the third cycle, the peaks position difference between the oxidation peak and the reduction peak decreases from 0.1021 to 0.0933 in the first cycle. For the battery without FEC and the reference electrolyte, the peaks position difference decreases from 0.1090 to 0.0988 and 0.1211 to 0.1281 , respectively, which shows that the reference electrolyte increases the polarization of the battery, and the $\mathrm{LiNi}_{0.5} \mathrm{Mn}_{1.5} \mathrm{O}_{4}$ electrode has a better intercalation and deintercalation performance in the electrolyte containing additives reversibility. It can be seen that the higher coulomb efficiency and rate performance was displayed during the charge and discharge process for the batter with FEC. In addition, from the second cycle, the CV curve area referring to the electrolyte with FEC is much larger than that to the reference electrolyte and the electrolyte without FEC. These phenomena show that the addition of FEC can

\section{A}

C

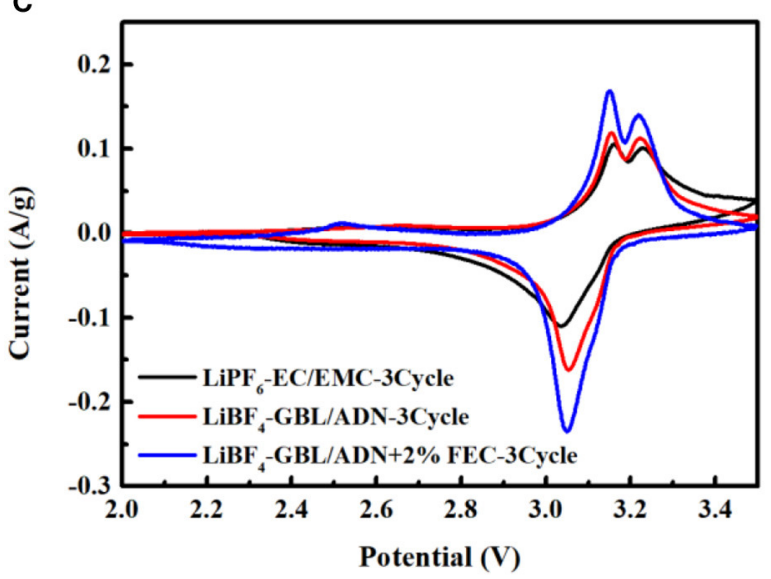

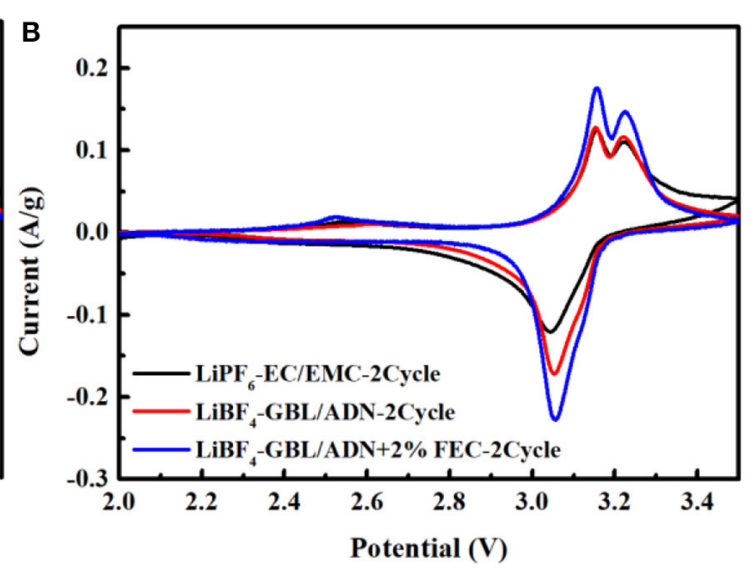

FIGURE 1 | CV curve of the first three cycles of three electrolytes for $\mathrm{LiNi}_{0.5} \mathrm{Mn}_{1.5} \mathrm{O}_{4} / \mathrm{Li}_{4} \mathrm{Ti}_{5} \mathrm{O}_{12}$ full-cells: (A) the first cycle; (B) the second cycle; (C) the third cycle. 
provide a higher reversible capacity, which is consistent with the above results.

As shown in Figure 2A, the LNMO half-cell is charged and discharged at room temperature in different electrolytes. To ensure the full performance of the battery, the battery is charged and discharged three cycles at a current intensity of $0.1 \mathrm{C}$ to achieve the purpose of activating the battery active material, and then cycle performance was obtained at $1 \mathrm{C}$. The purpose of adding FEC to the traditional electrolyte is used as a control group to judge the effect of FEC on the performance of the half-cell. It can be seen from the Figure $2 \mathbf{A}$ that in the initial three cycles of pre-circulation, the reference electrolyte and the comparison electrolyte 1st have a first-cycle discharge specific capacity of $102.7,103.6 \mathrm{mAh} \mathrm{g}^{-1}$. After at 100 cycles, the capacity retention rate of the comparison electrolyte 1st (74\%) is slightly higher than the reference electrolyte $(68 \%)$, which means that adding FEC to the reference electrolyte is beneficial to stabilize electrode/electrolyte interface. Similarly, the first-cycle discharge specific capacity with the comparison electrolyte 2 nd and the target electrolyte are 110.5 and $115.6 \mathrm{mAh} \mathrm{g}^{-1}$, respectively. After at 100 cycles, the capacity retention rate of the target electrolyte (83\%) is higher than the comparison electrolyte 2nd (77\%), which shows that target electrolyte has better electrochemical performance. It could be attributed to the positive electrode SEI film formed by FEC successfully restricting the direct contact between the electrode material and the electrolyte. The positive electrode SEI film could inhibit the decomposition of the electrolyte and the destruction of the electrode structure. Meanwhile, it is worth noting that the discharge specific capacity and capacity retention rate of the comparison electrolyte 2 nd are higher than the reference electrolyte and the comparison electrolyte 1st. It is reason that $\mathrm{ADN}$ has a higher oxidation potential, it is not easy to be oxidized compared to carbonate solvents, and a higher proportion of $\mathrm{ADN}$ in the electrolyte solution preferentially occupies the active sites on the surface of the positive electrode material to hinder more carbonate solvents break down (Zhou et al., 2016). FEC combined with ADN could form a protective film with stable interface, and effectively improve the cycle performance of the battery.

This rule can be found in the full battery, that the Figure $2 \mathrm{~B}$ is the cycle performance diagram of the LNMO/LTO full battery at room temperature for 100 cycles. The capacity retention rate and the specific discharge capacity of the target electrolyte (84\%, 96.9 $\left.\mathrm{mAh} \mathrm{g}^{-1}\right)$, and the comparison electrolyte $2 \mathrm{nd}$ (73\%, $93 \mathrm{mAh}$ $\mathrm{g}^{-1}$ ) are much higher than the reference electrolyte (63\%, 82.5 $\mathrm{mAh} \mathrm{g}^{-1}$ ). Whether it is the half-cell or the full-cell, because of the synergy of ADN and FEC, the battery shows excellent cycle performance.

With the widespread use of lithium-ion batteries, it is hoped that the battery can be fully charged in a shorter period. Therefore, higher requirements are placed on the power density of lithium-ion batteries, and the rate performance of the battery is the most important factor affecting its power density. Therefore, the development of an electrolyte with a good rate performance, is crucial to the further development of lithium ion batteries. Select the above ADN-based electrolyte and add FEC, using commercial electrolyte as a reference to further study its rate performance.

Figure $\mathbf{3 A}$ is the rate performance in different electrolytes of LNMO half-cells. When the current density increases, the discharge specific capacity gradually decreases. The main reason is that the heavily polarized at the large current density, and the polarization impedance increases rapidly. When the current density returns to $0.2 \mathrm{C}$, the discharge specific capacity also returns to the level of initial $0.2 \mathrm{C}$. Compared the target electrolyte with the comparison electrolyte 2nd shows the FEC additive not change the structure of the $\mathrm{LiNi}_{0.5} \mathrm{Mn}_{1.5} \mathrm{O}_{4}$ material after the battery undergoes rate cycling, and the electrode material is still intact.

The initial discharge specific capacity is $118.3,111.8,105.3$ $\mathrm{mAh} \mathrm{g}^{-1}$ for batteries with additives, no FEC and reference electrolytes, respectively. The target electrolyte shows more excellent rate performance, which is related to the synergistic effect of FEC and ADN. However, the effect of FEC is not obvious
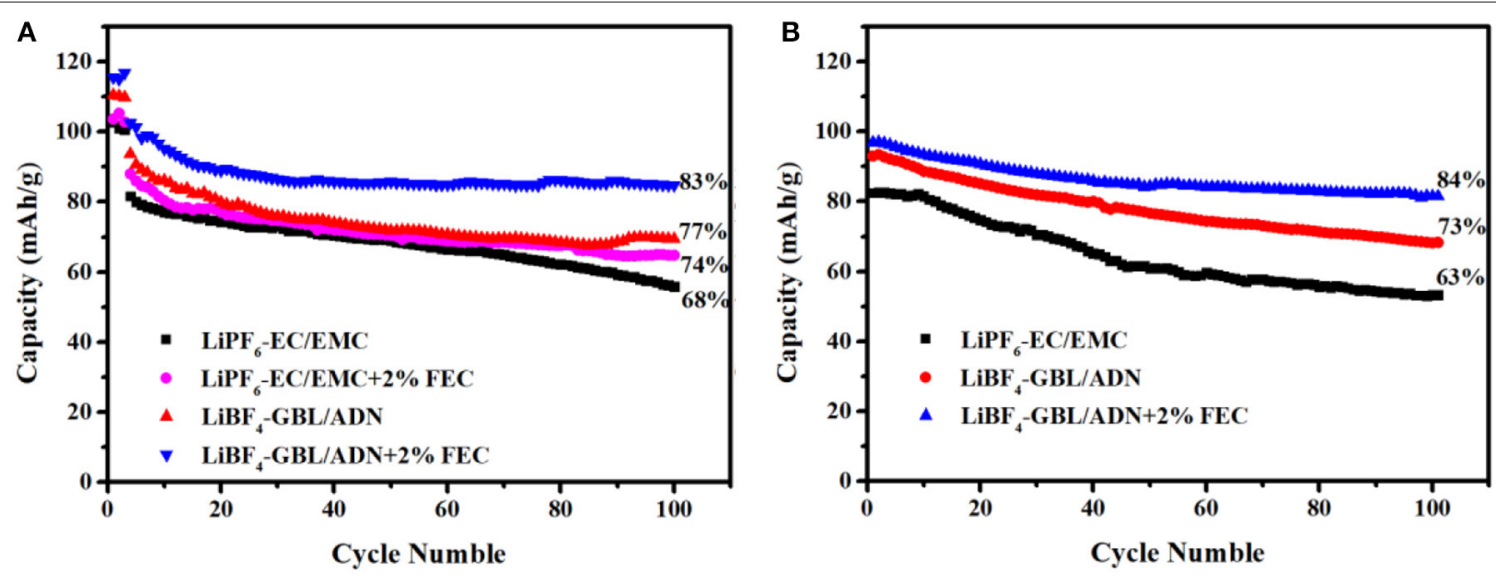

FIGURE 2 | $1 \mathrm{C}$ charge-discharge cycle performance in different electrolytes: (A) LNMO half-cells; (B) LNMO/LTO full-cells. 
at the high current intensity, which shows that the migration rate of active substances in the electrolyte cannot keep up with the rate of electrochemical reactions at high current intensity. So that the electrolyte cannot provide enough free ions for the electrode surface, resulting in a lower capacity.

Figure 3B is rate performance in different electrolytes LNMO/LTO full-cell. It is worth noting that the addition of FEC in the ADN-based electrolyte makes the battery play a greater advantage. At $2 \mathrm{C}$ current intensity, the specific discharge capacity of electrolytes with FEC, without FEC and reference electrolyte are 73.1, 65.4, and $48.1 \mathrm{mAh} \mathrm{g}^{-1}$, respectively, which are corresponding to $60.8,55.8$, and $53.1 \%$ at $0.1 \mathrm{C}$. Obviously, the adiponitrile synergistic fluoroethylene carbonate electrolyte has better compatibility for the full battery with $\mathrm{Li}_{4} \mathrm{Ti}_{5} \mathrm{O}_{12}$ as the negative electrode than the reference electrolyte at the high current intensity. It meets the higher requirement of power density application of lithium ion battery. The results showed that the full battery containing FEC electrolyte exhibits more excellent rate performance under high pressure, which is consistent with the results obtained from the half-cell research.
Figure $4 \mathrm{~A}$ is the first charge-discharge curve of $\mathrm{LNMO} / \mathrm{Li}$ half-cell in the range of $3.0-4.9 \mathrm{~V}$ at $0.1 \mathrm{C}$ current intensity. The specific discharge capacity of the battery with FEC electrolyte in the first cycle $\left(116.8 \mathrm{mAh} \mathrm{g}^{-1}\right)$ is better than that without FEC (113.9 $\mathrm{mAh}^{-1}$ ) and the reference electrolyte (107.5 $\left.\mathrm{mAh} \mathrm{g}^{-1}\right)$. It can be seen that the charge-discharge curve has two charge and discharge platforms of 4.0 and $4.7 \mathrm{~V}$ in three different electrolyte systems, the $4.0 \mathrm{~V}$ charge and discharge platform corresponds to the $\mathrm{Mn}^{4+} / \mathrm{Mn}^{3+}$ redox in the material. The $4.7 \mathrm{~V}$ charge and discharge platform belongs to the $\mathrm{Ni}^{4+} / \mathrm{Ni}^{2+}$ redox, and this platform is relatively stable. Compared with the reference electrolyte, the battery containing the FEC electrolyte has a higher coulomb efficiency (76.5\%) of the first cycle battery, which indicates that the addition of FEC has better chemical reaction kinetic activity in batteries. The electrolyte oxidizes and decomposes to produce an initial protective film, the protective film repairs and grows self during the battery proceeds. Finally, with the battery charge and discharge process continues, the interface film tends to stabilize and the oxidative decomposition of electrolyte gradually
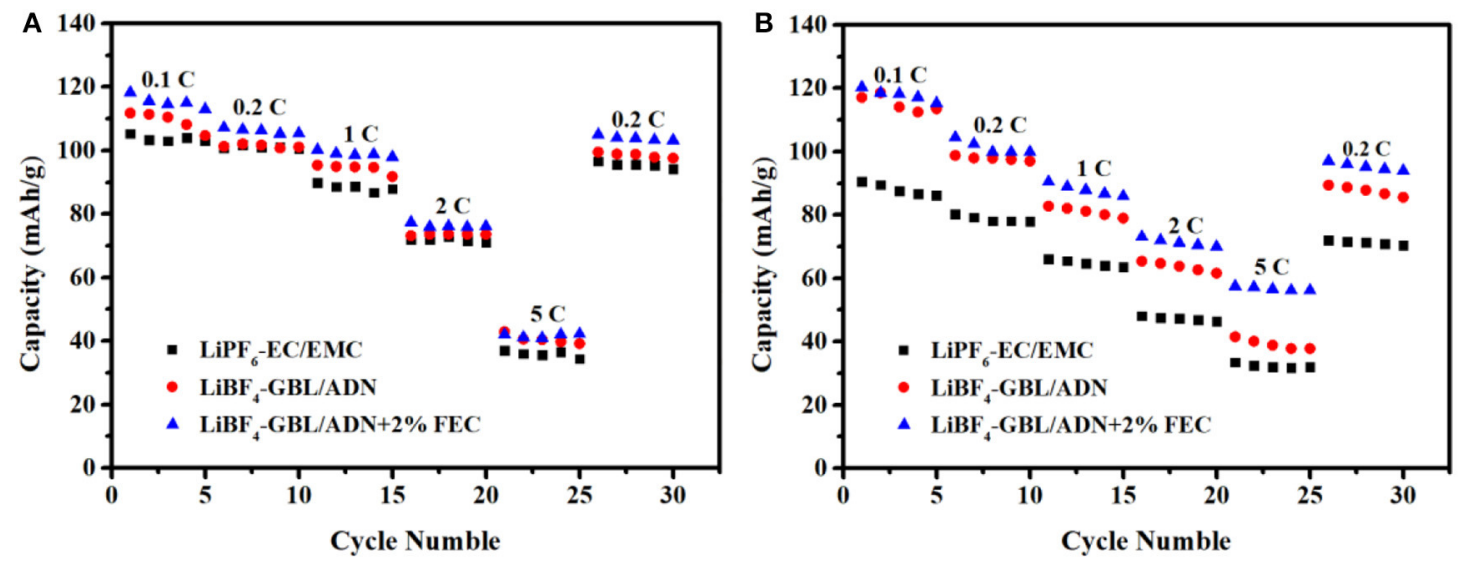

FIGURE 3 | Rate performance in different electrolytes: (A) LNMO half-cells; (B) LNMO/LTO full-cells.
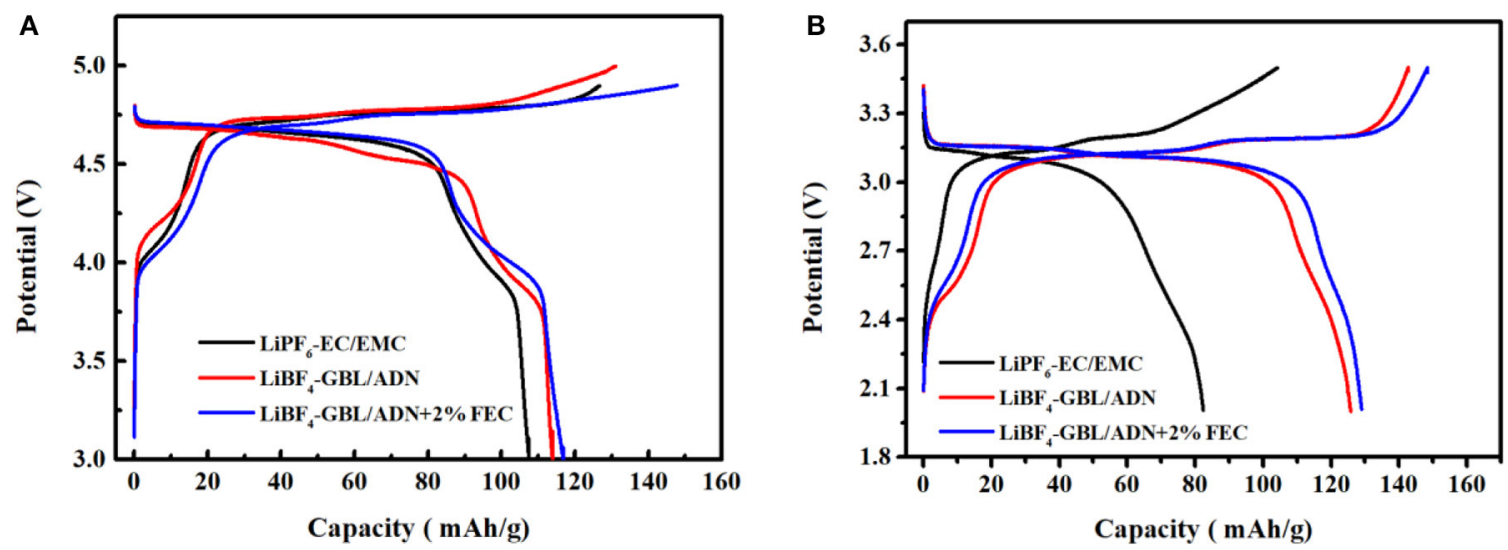

FIGURE 4 | Charge and discharge curve at the first cycle of three electrolytes at 0.1 C rate: (A) LNMO half-cells; (B) LNMO/LTO full-cells. 
suppressed, resulting in the columbic efficiency of the battery close to $100 \%$.

Figure 4B is the first charge-discharge curve of LNMO/LTO full battery. There are two charge-discharge platforms. The reference electrolyte has a weak redox platform in the $2.4-2.7 \mathrm{~V}$ range. This indicates that the reference electrolyte has almost no chemical reaction with manganese ions, rarely participates in the generation of SEI film on this platform, and consumes less electrolyte, which also shows that the battery led by the reference electrolyte has a low impedance at the beginning of the cycle. However, at the second charge and discharge platform $3.14-3.21 \mathrm{~V}$ corresponding to the $\mathrm{Ni}^{4+} / \mathrm{Ni}^{2+}$ redox couple, the reference electrolyte battery has a very low discharge platform compared to the other two ADN-based electrolyte batteries. Meanwhile, the charging platform is high and long, and the distance between the charge and discharge curves is large. This shows that the polarization is very large, the compatibility between the reference electrolyte and the LNMO full-cells with LTO as the negative electrode is not good, resulting in a low specific discharge capacity and coulomb efficiency $(82.4 \mathrm{mAh}$ $\mathrm{g}^{-1}$ and $\left.46.8 \%\right)$. For the ADN-based electrolyte battery, the distance between the charge and discharge curves is small and the platform is very stable, resulting in low polarization. Batteries with FEC electrolyte have better electrochemical stability, and the LNMO energy of FEC is relatively low, so reduction decomposition could occur at a higher electric potential, thus forming the SEI film with more stable composition and structure. Generally, better SEI film means the better cycling performance.

The EIS spectrum of a battery is usually described by four main characteristics. The high-frequency and intermediatefrequency flat semicircles can be attributed to the interface film (Rf) and lithium ion charge transfer (Rct) at the interface of the film and the active material (coupled to the thin film and/or interface capacitance). Low-frequency Warburg-type elements reflect the solid-state diffusion of lithium ions. Finally, at very low frequencies, the $\mathrm{Z}$ vs. $\mathrm{Z}^{\prime \prime}$ curve becomes a steep, almost vertical line, which reflects the capacitive behavior of the electrode (lithium ion insertion and corresponding charge transfer) (Ou et al., 2012). Figure 5A is the AC impedance measured by the LNMO half-cell before cycling. It can be seen that the interfacial resistance $(22.3 \Omega)$ of the reference electrolyte battery is the smallest. It means that in the initial formation reaction, the reference electrolyte not participate or rarely participates in the generation of SEI film on this platform, so that consumes less electrolyte. The battery with FEC electrolyte has a maximum interface impedance $(25.6 \Omega)$, which shows that FEC directly participates in the formation of the interface film and consumes a large amount of electrolyte, making the charge and discharge efficiency lower in the first cycle. This corresponds to the corollary of Figure 4. The formation of the film has double effects. On the one hand, the formation of the film consumes lithium ions in the electrolyte or electrode. The thickness of the film increased could improve the polarization of the battery, and resulting in a decrease of rate performance in battery. On the other hand, the formation of the film improves the cycle performance of the battery, especially when the film was formed stable and relatively thin, thereby improving the overall performance of the battery (Ma et al., 2018). Generally, the SEI film initially formed by the oxidative decomposition of the electrolyte after 10 cycles. As shown in Figure 5B, the resistance of the reference electrolyte increased to $57.6 \Omega$, the comparative electrolyte 2 nd and the target electrolyte increased to 43.1 and $40 \Omega$. It shows that FEC is more conducive to the formation of a stable SEI film, and inhibiting the continuous reaction between the electrolyte and the electrode consumes the electrolyte. Therefore, the lithium ions could to be effectively extracted and intercalated and improving the electrochemical performance of the battery.

In order to further explore the formation mechanism of the electrolyte interface film at the electrode/electrolyte interface, the $\mathrm{LiNi}_{0.5} \mathrm{Mn}_{1.5} \mathrm{O}_{4}$ batteries of the commercial electrolyte, the target electrolyte and the comparative electrolyte 2nd were disassembled after 10 and 100 cycles, respectively. The pole pieces were cleaned by the AN several times, and then transferred to the vacuum drying oven at $120^{\circ} \mathrm{C}$ for $2 \mathrm{~h}$. The uniformity of the interface film on the surface of the material and the changes
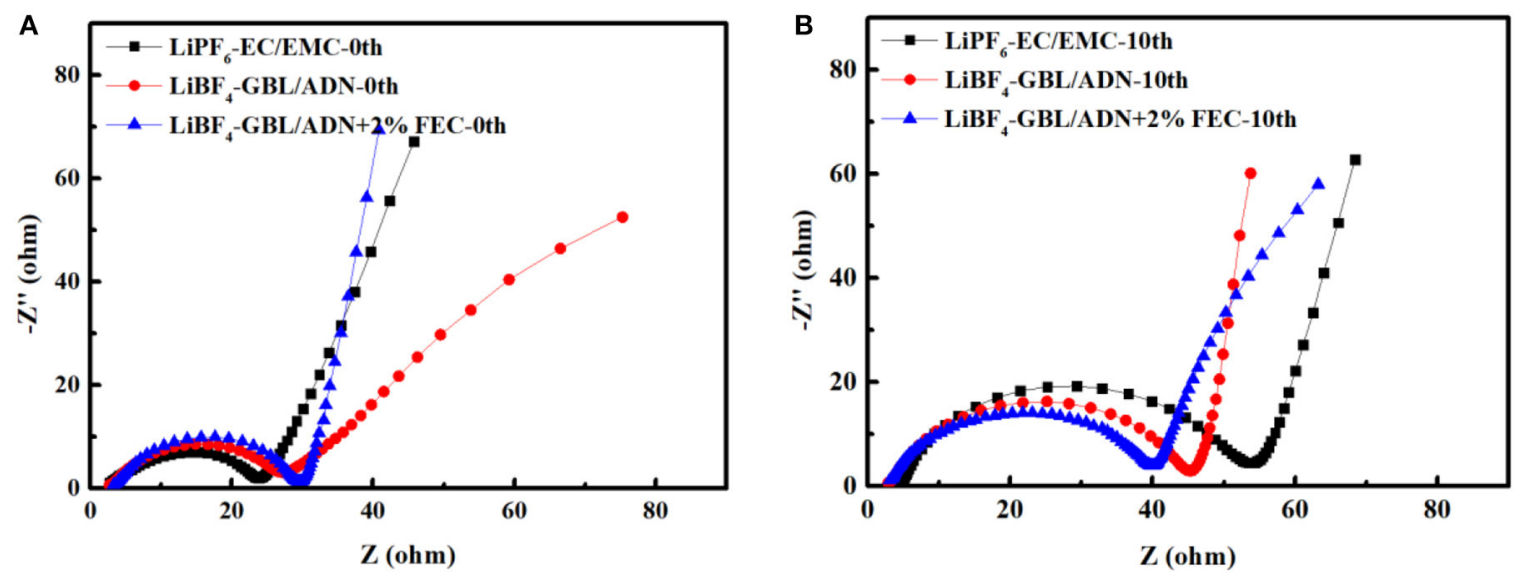

FIGURE 5 | EIS spectrum of LNMO/Li battery before and after $0.1 \mathrm{C}$ rate cycling: (A) before cycled; (B) after 10 cycles. 
in the structure are characterized by SEM. Figures $6 \mathbf{a}_{1}, \mathbf{a}_{2}$ are SEM images of $1.0 \mathrm{M} \mathrm{LiPF}_{6}-\mathrm{EC} / \mathrm{EMC}$ cathode surface after 10 and 100 cycles, respectively. It can be seen that the surface of the electrode is rough and fuzzy is due to the surface of the $\mathrm{LiNi}_{0.5} \mathrm{Mn}_{1.5} \mathrm{O}_{4}$ particles covered with electrolyte decomposition products, which polymerize into the film and adhere to the surface of the material unevenly. With the progress of reaction, the surface morphology of the material after the 100th was deeper than that of the 10th, and it shows that a slight collapse of the structure of $\mathrm{LiNi}_{0.5} \mathrm{Mn}_{1.5} \mathrm{O}_{4}$ material has a slight collapse and cracks in the particles (Ma et al., 2018). It could be the commercial electrolyte reacts the continuous oxidative decomposition reaction at $4.9 \mathrm{~V}$, and producing strong corrosive HF, which causes its different valences of nickel and manganese ions to dissolve in the electrolyte (Ou et al., 2012). As a result, the structure of the material was destroyed and the charge and discharge performance of the battery was reduced seriously. Similarly, in Figures $\mathbf{6}_{\mathbf{1}}, \mathbf{b}_{\mathbf{2}}$ that the surface of the battery pole piece after the cycle of the comparative electrolyte 2 not form a good morphology, the surface is relatively rough, and the formed interface film is not obvious. It could be because of the ADN not exert the advantage of high-voltage at the $4.9 \mathrm{~V}$ LNMO. However, its surface is better than the battery of the reference electrolyte.

In contrast, Figure $6 c_{1}$ shows the morphology of

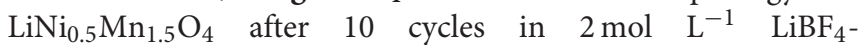
GBL/ADN $+2 \%$ FEC electrolyte. It can be clearly observed that a dense and uniform interface film is attached to the surface of the material, and it is flat and smooth. This interface film cane effectively prevents electron transport and solvent molecule shuttle, but provides a channel for the migration of lithium ions during the cycle, effectively isolating the electrolyte from contact with $\mathrm{LiNi}_{0.5} \mathrm{Mn}_{1.5} \mathrm{O}_{4}$ active particles, which further inhibits the decomposition of electrolyte and provide a good protection for the positive electrode. However, as shown in Figure $\mathbf{6 c}_{2}$, when the battery is cycled to 100 cycles, the smoothness of the interface film is impaired, which leads to an increase in

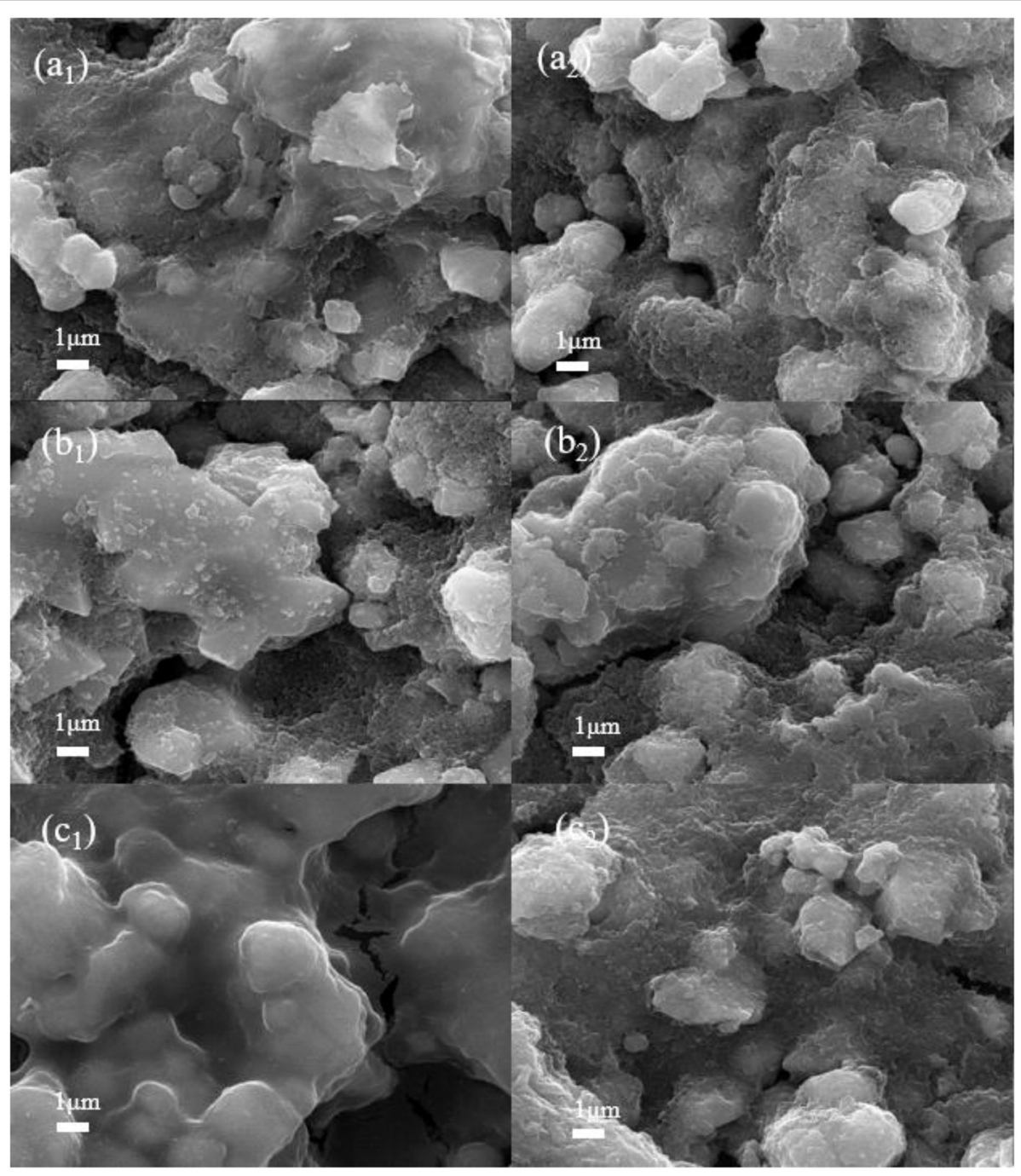

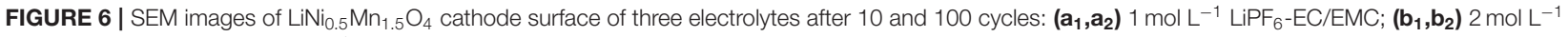
$\mathrm{LiBF}_{4}-\mathrm{GBL} / \mathrm{ADN} ;\left(\mathbf{c}_{\mathbf{1}}, \mathbf{c}_{\mathbf{2}}\right) 2 \mathrm{~mol} \mathrm{~L}^{-1} \mathrm{LiBF}_{4}-\mathrm{GBL} / \mathrm{ADN}+2 \% \mathrm{FEC}$. 
battery impedance and affects a decrease in discharge capacity. This trend is consistent in ADN-based batteries without FEC additives. In general, FEC electrolyte additives can promote the formation of a stable interface between electrode and electrolyte under the effect of ADN high pressure resistance, which is the reason for the FEC can improve battery performance as an electrolyte additive.

Figure 7 investigates the X-ray diffraction (XRD) pattern of $\mathrm{LiNi}_{0.5} \mathrm{Mn}_{1.5} \mathrm{O}_{4}$ after 20 cycles of three electrolytes. The diffraction peaks of the three samples are well-matched with the standard PDF\#80-2162 card of $\mathrm{LiNi}_{0.5} \mathrm{Mn}_{1.5} \mathrm{O}_{4}$ material, it shows that the pole piece material has not changed original spinel structure after the three electrolyte cycles. For the commercial electrolyte battery, the (111) diffraction peak of the material after cycling is relatively lowest, which indicates the commercial electrolyte cannot prevent the crystallinity of the material from decreasing at the high pressure of $4.9 \mathrm{~V}$. Because the lower crystallinity can affect the electrochemical performance of materials. Compared with the comparative electrolyte 2 battery, the pole piece of target electrolyte battery has a stronger intensity of the (111) diffraction peak, with the narrow half-width and sharp peak shape, which proves that its crystallinity is relatively good (Liu et al., 2015). According to reports in the literature, the ratio of the (311) diffraction peak to the (111) diffraction peak can determine the degree of material cation mixing. When the ratio is smaller, the structure of the material is more stable in a disordered state ( $\mathrm{Wu}$ et al., 2017). Based on calculation, the I (311)/I (111) values of commercial electrolyte batteries, target electrolyte batteries and comparative electrolyte are $0.766,0.753$, and 0.724 , respectively. It is indicating that the degree of cation mixing of batteries with FEC additives is lower, and the crystal structure is more stable.

Figure 8 is X-ray photoelectron spectroscopy (XPS) spectra of LiNi0.5Mn1.5O4 cathodes of $\mathrm{C} 1 \mathrm{~s}, \mathrm{O} 1 \mathrm{~s}, \mathrm{~F} 1 \mathrm{~s}$, and $\mathrm{N} 1 \mathrm{~s}$

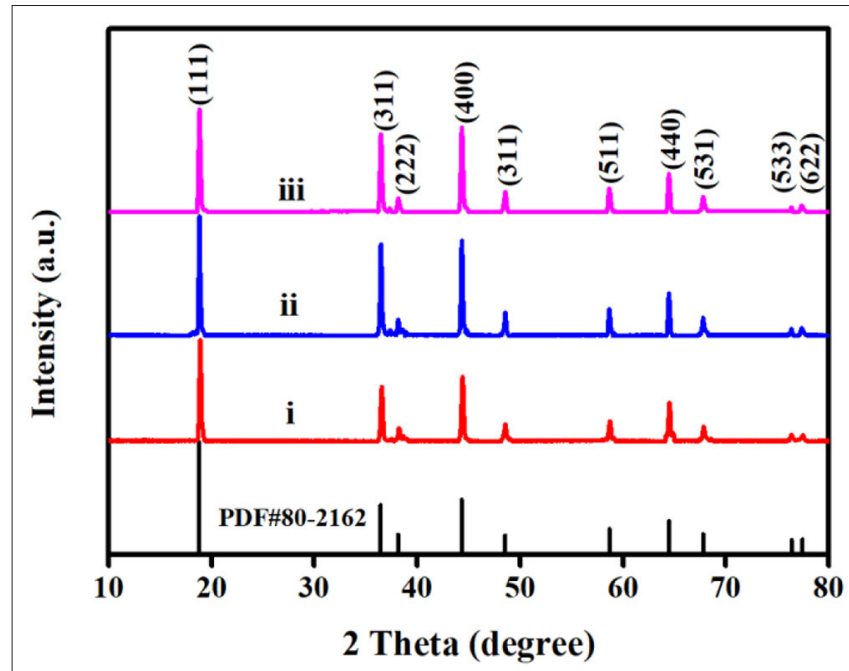

FIGURE $7 \mid X R D$ patterns of $\mathrm{LiNi}_{0.5} \mathrm{Mn}_{1.5} \mathrm{O}_{4}$ after 20 cycles with three electrolytes: (i) $1 \mathrm{~mol} \mathrm{~L}{ }^{-1} \mathrm{LiPF}_{6}-\mathrm{EC} / \mathrm{EMC}$; (ii) $2 \mathrm{~mol} \mathrm{~L}^{-1} \mathrm{LiBF}_{4}-\mathrm{GBL} / \mathrm{ADN}$; (iii) 2 $\mathrm{moL}^{-1} \mathrm{LiBF}_{4}-\mathrm{GBL} / \mathrm{ADN}+2 \% \mathrm{FEC}$. with three electrolytes after 20 cycles. In the $\mathrm{C} 1 \mathrm{~s}$ spectrum of the three electrolyte batteries, the peak at $285.4 \mathrm{eV}$ is attributed to alkyl lithium carbonate (C-O-C), and the peak at 290.8 and $287.8 \mathrm{eV}$ belong to inorganic lithium carbonate $(\mathrm{C}=\mathrm{O})$. During the cycle, the generation of peaks indicates that there are inorganic substances such as $\mathrm{Li}_{2} \mathrm{CO}_{3}$ and organic substances $\mathrm{ROCO}_{2} \mathrm{Li}$ and ROLi on the surface of the positive electrode
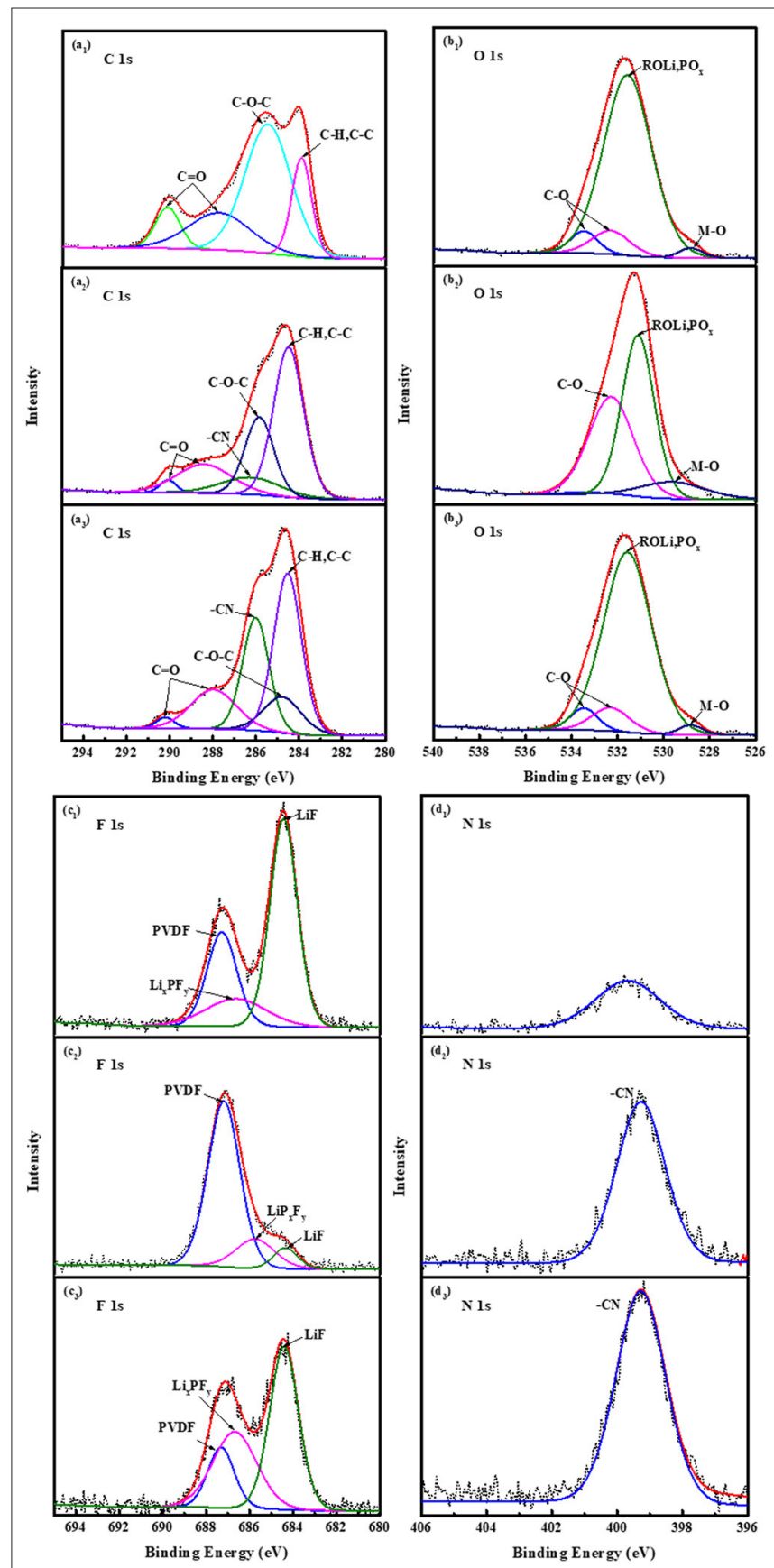

FIGURE 8 | XPS spectra of $\mathrm{LiNi}_{0.5} \mathrm{Mn}_{1.5} \mathrm{O}_{4}$ cathodes of $\mathrm{C} 1 \mathrm{~s}, \mathrm{O} 1 \mathrm{~s}, \mathrm{~F}$ 1s and $\mathrm{N} 1 \mathrm{~s}$ with three electrolyte after 20 cycles: $\left(\mathbf{a}_{\mathbf{1}}-\mathbf{d}_{\mathbf{1}}\right) 1 \mathrm{~mol} \mathrm{~L}{ }^{-1} \mathrm{LiPF}_{6}-\mathrm{EC} / \mathrm{EMC}$; $\left(\mathbf{a}_{\mathbf{2}}-\mathbf{d}_{\mathbf{2}}\right) 2 \mathrm{~mol} \mathrm{~L}^{-1} \mathrm{LiBF}_{4}-\mathrm{GBL} / \mathrm{ADN} ;\left(\mathbf{a}_{\mathbf{3}}-\mathbf{d}_{\mathbf{3}}\right) 2 \mathrm{~mol} \mathrm{~L}^{-1}$ $\mathrm{LiBF}_{4}-\mathrm{GBL} / \mathrm{ADN}+2 \% \mathrm{FEC}$. 
material, which mainly come from the decomposition products of lithium carbonate, lithium carbonate electrolyte and trace water (Rong et al., 2014; Zhang et al., 2016). The existence of these substances can be further proved in the $\mathrm{O}$ 1s spectrum, the $\mathrm{C}-\mathrm{O}$ peak is at $534.2 \mathrm{eV}$, and the $\mathrm{C}=\mathrm{O}$ peak is at $532.8 \mathrm{eV}$ (Eriksson et al., 2002). It is worth noting that the $\mathrm{C}-\mathrm{O}-\mathrm{C}$ on the surface of the electrode with FEC is weak, and the $\mathrm{C}=\mathrm{O}$ peak is strong, which shows that FEC effectively inhibits the oxidative decomposition of the electrolyte. It is the same as the tendency of the $\mathrm{C}-\mathrm{O}$ peak in the $\mathrm{O} 1 \mathrm{~s}$ spectrum to be weak. The peak at $284.5 \mathrm{eV}$ in the $\mathrm{C} 1 \mathrm{~s}$ spectrum is attributed to the $\mathrm{C}-\mathrm{C}$ bond in the hydrocarbon $(\mathrm{C}-\mathrm{H})$ and conductive carbon black (An et al., 2011; Ha et al., 2013). In addition, in the C 1s spectrum of the battery material containing $\mathrm{ADN}$ groups, as shown in Figures $8 \mathbf{a}_{2}, \mathbf{a}_{3}$, the presence of the $-\mathrm{CN}$ group was detected at $286.5 \mathrm{eV}$, which also corresponds to $399.5 \mathrm{eV}$ in the $\mathrm{N} 1 \mathrm{~s}$ spectrum (Deniau et al., 1992). At the high-pressure conditions, it fully indicates that $\mathrm{ADN}$ molecules directly participate in the formation of the positive electrode interface film. The $-\mathrm{CN}$ group is the main component of the SEI film, which ensures the migration of lithium ions between the positive and negative electrodes, and it is beneficial to improve the cycling stability of the electrode.

As shown in Figure $\mathbf{8 c}_{\mathbf{1}}$, the characteristic peak at $687.9 \mathrm{eV}$ belongs to the C-F bond in PVDF, and the strong peak at $684.5 \mathrm{eV}$ belongs to $\mathrm{LiF}$ in the $\mathrm{F}_{1 \mathrm{~s}}$ spectrum. Inorganic LiF mainly comes from the thermal decomposition reaction of lithium salt $\mathrm{LiPF}_{6}$ and trace water in the electrolyte (Han et al., 2010; Li et al., 2013). It will be accompanied by the formation of highstrength corrosive acid (HF). The corrosive acid will initiate a series of autocatalytic decomposition reactions involving the electrolyte and the transition metal oxide cathode, and severely destroying the formation of the interface film. Compared with the other two ADN-based electrolyte electrodes, the LiF peak containing $\mathrm{LiPF}_{6}$ is relatively strong, resulting in a strong charge impedance, indicating the reason why the traditional electrolyte has poor cycling stability for $\mathrm{LiNi}_{0.5} \mathrm{Mn}_{1.5} \mathrm{O}_{4}$ material at the high voltage of $4.9 \mathrm{~V}$. As shown in Figures $8 \mathbf{c}_{2}, \mathbf{c}_{3}$, it also corresponds to $\mathrm{LiF}$ at $684.5 \mathrm{eV}$, which is the selfdecomposition reaction from $\mathrm{LiBF}_{4}$. For the $\mathrm{LiF}$ peak containing FEC electrolyte batteries, a small part is the self-decomposition reaction of $\mathrm{LiBF}_{4}$, and more is the fluorine group in the fluoroethylene carbonate. The group has a strong electronwithdrawing ability. At higher reduction potentials, fluorinecontaining substances such as $\mathrm{Li}_{\mathrm{x}} \mathrm{PF}_{\mathrm{y}}$ and $\mathrm{LiF}$ (Michan et al., 2016) generated by the reaction preferentially occupy the active site of $\mathrm{LiNi}_{0.5} \mathrm{Mn}_{1.5} \mathrm{O}_{4}$, meanwhile, it suppress low reduction potential electrolyte solvents break down. The XPS results further show that the ADN-based electrolyte containing FEC additives makes the positive electrode $\mathrm{LiNi}_{0.5} \mathrm{Mn}_{1.5} \mathrm{O}_{4}$ beneficial to the

\section{REFERENCES}

Abu-Lebdeh, Y., and Davidson, I. (2009). High-voltage electrolytes based on adiponitrile for Li-ion batteries. J. Power Sources 156, A60-A65. doi: 10.1016/j.jpowsour.2008.09.113

An, Y., Zuo, P., Cheng, X., Liao, L., and Yin, G. (2011). The effects of LiBOB additive for stable SEI formation of formation of the SEI film, and improves the cycle stability and rate performance.

\section{CONCLUSIONS}

The electrochemical performance referring to $5 \mathrm{~V}$-level $\mathrm{LiNi}_{0.5} \mathrm{Mn}_{1.5} \mathrm{O}_{4}$ cathode material was studied in the high voltage electrolyte system (2 mol $\left.\mathrm{L}^{-1} \quad \mathrm{LiBF}_{4}-\mathrm{GBL} / \mathrm{ADN}+2 \% \quad \mathrm{FEC}\right)$. Compared with the traditional commercial electrolyte and FECfree electrolyte systems, the FEC system can improve the battery cycle stability. At $1 \mathrm{C}$ rate, the 100 -cycled capacity retention rate can reach $83 \%$, while the capacity retention rate without FEC system and commercial electrolyte system is only $77 \%$ and $68 \%$, and the rate performance has been improved. The results of EIS and CV curves for $\mathrm{LiNi}_{0.5} \mathrm{Mn}_{1.5} \mathrm{O}_{4}$ batteries show that the synergistic effect of ADN and FEC can reduce their polarization at high voltages. The interface film between the electrolyte and the electrode tends to be stable, thus reducing capacity loss and improving battery electrochemical performance. Fluorine can preferentially occupy the active site of $\mathrm{LiNi}_{0.5} \mathrm{Mn}_{1.5} \mathrm{O}_{4}$ and inhibit the decomposition of the electrolyte with low reduction potential, finally stabilizing the electrochemical performance of the electrode. The electrochemical performance of $\mathrm{LiNi}_{0.5} \mathrm{Mn}_{1.5} \mathrm{O}_{4} / \mathrm{Li}_{4} \mathrm{Ti}_{5} \mathrm{O}_{12}$ in the high-voltage electrolyte mentioned above shows that FEC is a good film-forming additive with a wide $\mathrm{ADN}$ window at high voltage. It has a good compatibility for all battery materials capacitive and plays an important role in promoting the application of high-voltage batteries.

\section{DATA AVAILABILITY STATEMENT}

All datasets presented in this study are included in the article/supplementary material.

\section{AUTHOR CONTRIBUTIONS}

$\mathrm{ZF}, \mathrm{ZZ}$, and WC proposed the idea. ZZ, WC, and $\mathrm{XZ}$ prepared all materials. ZZ, WC, and $\mathrm{KZ}$ conducted electrochemical experiments and analyzed the data. $\mathrm{ZF}, \mathrm{ZZ}, \mathrm{WC}$, and $\mathrm{XZ}$ wrote the manuscript. ZF, WC, and LL supervised the implementation of the study. All authors contributed to this article and approved the submitted version.

\section{FUNDING}

This work was supported by the National Natural Science Foundation of China (51974219), Natural Science Basic Research Plan in Shaanxi Province (2018JM5135).

PP13TFSI-organic mixed electrolyte in lithium ion batteries. Electrochim. Acta 56, 4841-4848. doi: 10.1016/j.electacta.201 1.01 .125

Arunkumar, T. A., and Manthiram, A. (2005). Influence of chromium doping on the electrochemical performance of the $5 \mathrm{and} \# \mathrm{xa} 0 ; \mathrm{V}$ spinel cathode LiMn1.5Ni0.5O4. Electrochim. Acta 50, 5568-5572. doi: 10.1016/j.electacta.200 5.03 .033 
Choi, N. S., Yew, K. H., Lee, K. Y., Sung, M., Kim, H., and Kim, S. S. (2006). Effect of fluoroethylene carbonate additive on interfacial properties of silicon thin-film electrode. J. Power Sources 161, 1254-1259. doi: 10.1016/j.jpowsour.2006.05.049

Deniau, G., Lecayon, G., Viel, P., Hennico, G., and Delhalle, J. (1992), Comparative study of acrylonitrile, 2-butenenitrile, 3-butenenitrile, and 2methyl-2-propenenitrile electropolymerization on a nickel cathode. Langmuir 8, 267-276. doi: 10.1021/la00037a050

Douaa, F., Julia, M., Henrik, E., Kristina, E. M., Daniel, L., and Fouad, G. (2018). Towards high-voltage Li-ion batteries: reversible cycling of graphite anodes and Li-ion batteries in adiponitrile-based electrolytes. Electrochim. Acta 281, 299-311. doi: 10.1016/j.electacta.2018.05.133

Duncan, H., Salem, N., and Abu-Lebdeh, Y. (2013). Electrolyte formulations based on dinitrile solvents for high voltage Li-ion batteries. J. Electrochem. Soc. 160, A838-A848. doi: 10.1149/2.088306jes

Ehteshami, N., Eguia-Barrio, A., de Meatza, I., Porcher, W., and Paillard, E. (2018). Adiponitrile-based electrolytes for high voltage, graphite-based Li-ion battery. J. Power Sources 397, 52-58. doi: 10.1016/j.jpowsour.2018.07.004

Eriksson, T., Andersson, A. M., Bishop, A. G., Gejke, C., Gustafsson, T., and Thomas, J. O. (2002). Surface analysis of LiMn2 O 4 electrodes in carbonatebased electrolytes. J. Electrochem. Soc 149, A69-A78. doi: 10.1149/1.1426398

Ha, S. Y., Han, J. G., Song, Y. M., Chun, M. J., Han, S. I., Shin, W. C., et al. (2013). Using a lithium bis(oxalato) borate additive to improve electrochemical performance of high-voltage spinel LiNi0.5Mn1.5O4 cathodes at $60^{\circ}$ C. Electrochim. Acta 104, 170-177. doi: 10.1016/j.electacta.2013.04.082

Han, G. B., Ryou, M. H., Cho, K. Y., Yong, M. L., and Park, J. K. (2010). Effect of succinic anhydride as an electrolyte additive on electrochemical characteristics of silicon thin-film electrode. J. Power Sources 95, 3709-3714. doi: 10.1016/j.jpowsour.2009.11.142

Isken, P., Dippel, C., Schmitz, R., Schmitz, R. W., Kunze, M., Passerini, S., et al. (2011). High flash point electrolyte for use in lithium-ion batteries. Electrochim. Acta 56, 7530-7535. doi: 10.1016/j.electacta.2011.06.095

Kim, J.-H., Myung, S.-T., Yoon, C. S., Kang, S. G., and Sun, Y. (2004). Comparative study of LiNi0.5Mn1.5O4- $\delta$ and LiNi0.5Mn1.5O4 cathodes having two crystallographic structures: Fd3m and P4332. Cheminform 16, 906-914. doi: 10.1002/chin.200421010

Kirshnamoorthy, A. N., Oldiges, K., Winter, M., Heuer, A., Cekic-Laskovic, I., Holm, C., et al. (2018). Electrolyte solvents for high voltage lithium ion batteries: ion correlation and specific anion effects in adiponitrile. Phys. Chem. Chem. Phys. 20, 25701-25715. doi: 10.1039/C8CP04102D

Li, Y., Xu, G., Yao, Y., Xue, L., Zhang, S., Lu, Y., et al. (2013). Improvement of cyclability of silicon-containing carbon nanofiber anodes for lithium-ion batteries by employing succinic anhydride as an electrolyte additive. J. Solid State Electrochem. 17, 1393-1399. doi: 10.1007/s10008-013-2005-7

Liu, B. S., Wang, Z. B., Zhang, Y., Yu, F. D., and Li, F. F. (2015). Preparation of submicrocrystal LiMn2O4 used $\mathrm{Mn} 3 \mathrm{O} 4$ as precursor and its electrochemical performance for lithium ion battery. J. Alloys Compd. 622, 902-907. doi: 10.1016/j.jallcom.2014.11.004

Lu, D., Xu, G., Hu, Z., Cui, Z., Wang, X., Li, J., et al. (2019). Deciphering the interface of a high-voltage (5 V-Class) Li-ion battery containing additive-assisted sulfolane-based electrolyte. Small Methods 3:1900546. doi: 10.1002/smtd.201900546

Ma, Y., Wang, L., Zuo, X., and Nan, J. (2018). Co-precipitation spraydrying synthesis and electrochemical performance of stabilized LiNi0.5Mn1.5O4 cathode materials. J. Solid State Electrochem. 22, 1963-1969. doi: 10.1007/s10008-018-3884-4

Manthiram, A., Chemelewski, K., and Lee, E. S. (2014). A perspective on the high-voltage LiMn_(1.5)Ni_(0.5)O_4 spinel cathode for lithium-ion batteries. Energy Environ. Sci. 7, 1339-1350. doi: 10.1039/c3ee42981d

Markevich, E., Salitra, G., Fridman, K., Sharabi, R., Gershinsky, G., Garsuch, A., et al. (2014). Fluoroethylene carbonate as an important component in electrolyte solutions for high-voltage lithium batteries: role of surface chemistry on the cathode. Langmuir ACS J. Surf. Colloids 30, 7414-7424. doi: $10.1021 / \mathrm{la} 501368 \mathrm{y}$
Michan, A. L., Parimalam, B. S., Leskes, M., Kerber, R. N., Yoon, T., Grey, C. P., et al. (2016). Fluoroethylene carbonate and vinylene carbonate reduction: understanding lithium-ion battery electrolyte additives and solid electrolyte interphase formation. Chem. Mater. 28, 8149-8159. doi: 10.1021/acs.chemmater.6b02282

Ou, S., Wang, S., Zhi, Q., Wei, Y., Tang, Z., Qiang, X., et al. (2012). Synthesis of spinel LiNio.5Mn1.5O4 cathode material with excellent cycle stability using urea-based sol-gel method. Mater. Lett. 89, 251-253. doi: 10.1016/j.matlet.2012.08.126

Rong, H., Xu, M., Xing, L., and Li, W. (2014). Enhanced cyclability of LiNi_(0.5)Mn_(1.5)O_4 cathode in carbonate based electrolyte with incorporation of tris(trimethylsilyl)phosphate (TMSP). J. Power Sources 261, 148-155. doi: 10.1016/j.jpowsour.2014.03.032

Santhanam, R., and Rambabu, B. (2010). Research progress in high voltage spinel LiNio.5Mn1.5O4 material. J. Power Sources 195, 5442-5451. doi: 10.1016/j.jpowsour.2010.03.067

Sawai, K., and Ohzuku, T. (2003). Factors affecting rate capability of graphite electrodes for lithium-ion batteries. J. Electrochem. Soc. 150, A674-A678. doi: $10.1149 / 1.1568107$

Talyosef, Y., Markovsky, B., Lavi, R., Salitra, G., and Stoyanova, R. (2007). Comparing the behavior of nano- and microsized particles of LiMn1.5Ni0.5O4 spinel as cathode materials for li-ion batteries. J. Electrochem. Soc. 154:A682. doi: 10.1149/1.2736657

Ufheil, J., Baertsch, M. C., Würsig, A., and Novák, P. (2005). Maleic anhydride as an additive to $\gamma$-butyrolactone solutions for Li-ion batteries. Electrochim. Acta 50, 1733-1738. doi: 10.1016/j.electacta.2004.10.061

Wang, H. (2015). LiNi0.5Mn1.5O4 cathodes for lithium ion batteries: a review. $J$. Nanosci. Nanotechnol. 15:6883. doi: 10.1166/jnn.2015.10726

Wu, B., Ren, Y., and Mu, D. (2013). Enhanced electrochemical performance of LiFePO4cathode with the addition of fluoroethylene carbonate in electrolyte. J.Solid State Electrochem. 17, 811-816. doi: 10.1007/s10008-012-1927-9

Wu, Y., Zhang, J., Cao, C., Khalid, S., Zhao, Q., Wang, R., et al. (2017). LiNi0.5Mn1.5O4 nano-submicro cubes as high-performance $5 \mathrm{~V}$ cathode materials for lithium-ion batteries. Electrochim. Acta 230, 293-298. doi: 10.1016/j.electacta.2017.01.124

Xiang, H. F., Jin, Q. Y., Wang, R., Chen, C. H., and Ge, X. W. (2008). Nonflammable electrolyte for $3-\mathrm{V}$ lithium-ion battery with spinel materials LiNi0.5Mn1.5O4 and Li4Ti5O12. J. Power Sources 179, 351-356. doi: 10.1016/j.jpowsour.2007.12.089

Yoon, T., Park, S., Mun, J., Ji, H. R., Choi, W., Kang, Y. S., et al. (2012). Failure mechanisms of LiNi0.5Mn1.5O4 electrode at elevated temperature. J. Power Sources 215, 312-316. doi: 10.1016/j.jpowsour.2012.04.103

Zhang, Y.-C., You, Y., Xin, S., Yin, Y.-X., Zhang, J., Wang, P., et al. (2016). Rice husk-derived hierarchical silicon/nitrogen-doped carbon/carbon nanotube spheres as low-cost and high-capacity anodes for lithium-ion batteries. Nano Energy 25, 120-127. doi: 10.1016/j.nanoen.2016.04.043

Zhou, L., Zhao, D., and Lou, X. W. (2012). LiNi0.5Mn1.5O4 hollow structures as high-performance cathodes for lithium-ion batteries. Angew. Chem. Int. Ed. 51, 239-241. doi: 10.1002/anie.201106998

Zhou, Y., Guo, H., Yang, Y., Wang, Z., Li, X., Zhou, R., et al. (2016). Facile synthesis of silicon/carbon nanospheres composite anode materials for lithiumion batteries. Mater. Lett. 168, 138-142. doi: 10.1016/j.matlet.2016.01.009

Conflict of Interest: The authors declare that the research was conducted in the absence of any commercial or financial relationships that could be construed as a potential conflict of interest.

Copyright (C) 2020 Fang, Zheng, Cheng, Zhang, Zhong and Li. This is an open-access article distributed under the terms of the Creative Commons Attribution License (CC BY). The use, distribution or reproduction in other forums is permitted, provided the original author(s) and the copyright owner(s) are credited and that the original publication in this journal is cited, in accordance with accepted academic practice. No use, distribution or reproduction is permitted which does not comply with these terms. 